\title{
Salt Concentration Effect on Electrical and Dielectric Properties of Solid Polymer Electrolytes based Carboxymethyl Cellulose for Lithium-ion Batteries
}

\author{
Ahmad Sofyan Sulaeman ${ }^{1, *}$, Akhiruddin Maddu ${ }^{1, *}$, Setyanto Tri Wahyudi ${ }^{1}$, Abdulloh Rifai ${ }^{2}$ \\ 1 Department of Physics, Faculty of Mathematics and Natural Sciences, IPB University, Bogor 166680 Indonesia \\ ahmadsofyansulaeman@gmail.com (A.S.S); stwahyudi@apps.ipb.ac.id (S.T.W); akhiruddin@apps.ipb.ac.id (A.M); \\ 2 Research Center for Physics, Indonesian Institute of Sciences, Puspitek, South Tangerang, Banten 15314 Indonesia; \\ abdu076@lipi.go.id (A.R); \\ * Correspondence: ahmadsofyansulaeman@gmail.com (A.S.S.), akhiruddin@apps.ipb.ac.id (A.M.); \\ Scopus Author ID 57207854097 (A.S.S); 23477443900 (A.M); \\ Received: 14.07.2021; Revised: 28.09.2021; Accepted: 2.10.2021; Published: 4.11.2021
}

\begin{abstract}
Solid polymer electrolytes (SPEs) based carboxymethyl cellulose (CMC) with lithium perchlorate $\left(\mathrm{LiClO}_{4}\right)$ were prepared via solution drop-cast technique. The CMC host is complexed by different concentrations of $\mathrm{LiClO}_{4}$ salt. SPEs were characterized by Electrochemical Impedance Spectroscopy (EIS) and Linear Sweep Voltammetry (LSV) in coin cells with lithium metal electrodes. EIS performed unique results based on various ionic conductivity values and dielectric properties. The higher ionic conductivity $\left(1.32 \times 10^{-5} \mathrm{~S} / \mathrm{cm}\right)$ was obtained by SPEs 2 following by short-range ionic transport results based on dielectric properties depending on frequency. SPEs with $\mathrm{LiClO}_{4}$ addition are electrochemically stable over $2 \mathrm{~V}$ in lithium battery coin cells from LSV results.
\end{abstract}

Keywords: solid polymer electrolytes; electrical conductivity; dielectric properties; electrochemical stability; lithium-ion batteries.

(C) 2021 by the authors. This article is an open-access article distributed under the terms and conditions of the Creative Commons Attribution (CC BY) license (https://creativecommons.org/licenses/by/4.0/).

\section{Introduction}

In the modern world, lithium-ion batteries (LIBs) have become one of the most promising approaches in the renewable energy development era since their introduction in 1991 by SONY corporation [1]. LIBs paid much attention due to their high energy density with broad application range such as electric vehicles, solar cells, and portable electronic devices [2,3]. Thus, the great demands of LIBs are intensively focused by researchers to obtain high safety, high capacity, long-life duration, and simpler packaging [1,4]. An effort to study is examining the specific parts of LIBs, especially electrolyte as a Li-ions medium transport.

The electrolyte is the main component in a battery system due to its role in separating electrodes and as an ion transporter during cell operation. Mostly, liquid electrolyte and organic salts were used in LIBs such as $\mathrm{LiPF}_{6}$ and carbonate solvents [5,6], but it has some obstacles such as triggering an internal short circuit, highly volatile, flammable at $>60{ }^{\circ} \mathrm{C}$, safety hazard, and poor packaging [5,7]. Therefore, eco-friendly solid polymer electrolytes (SPEs) are prominently proposed to substitute traditional electrolytes [8,9]. This purpose of start in developing solid-state Li-ion batteries [10,11]. 
The eco-friendly SPEs based on natural polymers have received great attention due to their potential for LIBs with high energy density [12,13]. It has several advantages: being nontoxic, low cost, low-vapor-pressure, non-flammable, biodegradable, and good flexibility [1416]. Various SPEs based natural polymers such as chitosan [17], starch [18], cellulose [19], methylcellulose [20,21], and carboxymethyl cellulose (CMC) [22] have been extensively studied, previously. However, the electrical conductivity of SPEs-based natural polymer still has to improve more than $10^{-3} \mathrm{~S} / \mathrm{cm}$ at room temperature because it is the requirement to be used in electrochemical applications [23]. This phenomenon may deal with the weakness of understanding about conduction mechanism in SPEs [8,24]. Theoretically, the electrical conductivity of SPEs depends on the density of charge carriers and carrier mobility resulting from the dipoles polarization process in the host polymer [25-27]. These parameters can be constructed with salts addition at certain concentrations. In order to complete particular information of ion conduction mechanism in SPEs, the presence of dielectric properties is important to obtain [28]. Hence, in this study, we provide electrical and dielectric properties of SPEs-based CMC complexed $\mathrm{LiClO}_{4}$ at different concentration. Complex impedance, dielectric permittivity, loss tangent, and electrochemical stability have been investigated to explain Li ionic transport mechanism in SPEs-based CMC-LiClO 4 .

\section{Materials and Methods}

\subsection{Materials.}

Lithium perchlorate anhydrous $\left(\mathrm{LiClO}_{4}\right.$ : purity: 97.0\%, KANTO CHEMICAL CO., INC, Japan) was used as a lithium salt. CMC technical grade for Li-ion Battery (Mw: 400,000 g/mol; DS: 0.98) and CA technical grade (Mw: 192,12 g/mol) from alibaba.com were used as host polymer and crosslinker, respectively.

\subsection{SPEs membranes preparation.}

CMC solution with $2 \%(\mathrm{w} / \mathrm{v})$ concentration was prepared in $30 \mathrm{~mL}$ deionized water under stirring at $50{ }^{\circ} \mathrm{C}$ for 6 hours. $\mathrm{CMC}$ solution is mixed with $\mathrm{LiClO}_{4}$ at different concentrations (Table 1) under stirring at room temperature. The homogenous solution is cast into a Petri dish with $60 \mathrm{~mm}$ diameter and dried at $40{ }^{\circ} \mathrm{C}$ overnight. The prepared membranes are cut into circular $(d=19 \mathrm{~mm})$ pieces and stored in a vacuum desiccator for 1 day. Then, all circular pieces through an assembly process in the standard glove box (Vigor Tech, USA; glove ports: Alumunium; O-type sealing ring $d=220 \mathrm{~mm}$ ) with lithium metal electrodes and punched to obtain coin cells in Argon atmosphere.

\subsection{Characterization.}

Electrical and dielectric properties measurements on the prepared SPEs membranes were carried out in the frequency range of $0.1 \mathrm{~Hz}$ to $50 \mathrm{MHz}$ using an impedance analyzer (Methrohm Autolab with Nova 1.11 software) which integrated a computer. Meanwhile, potential stability is measured with Linear Sweep Voltammetry (WBCS 3000) in $5 \mathrm{mV} . \mathrm{s}^{-1}$ scan rates under AC voltage.

Table 1. List of sample names with different $\mathrm{LiClO}_{4}$ concentration.

\begin{tabular}{l|l} 
Sample names & Description \\
\hline SPEs 1 & $2 \% \mathrm{CMC}+0 \% \mathrm{LiClO}_{4}$ \\
\hline SPEs 2 & $2 \% \mathrm{CMC}+10 \% \mathrm{LiClO}_{4}$ \\
\hline
\end{tabular}




\section{Results and Discussion}

\subsection{Complex impedance analysis.}

The impedance analysis is a meaningful technique for understanding the charge transport process of ion-conducting materials such as SPEs and electrodes to obtain bulk resistance $\left(R_{b}\right)$ [29,30]. EIS is commonly displayed in Nyquist plot ( $Z^{\prime \prime}$ vs $Z^{\prime}$ ) as can be seen in Figure 1. Nevertheless, we provide electrical equivalent circuits (EECs) models to knowing more deeply about ion-conduction mechanism in this SPEs. The high semi-circle and half semicircle curves in SPEs 1 (Figure 1.a) assigned as bulk conductance effect and ion diffusion in SPEs 1 . It is clearly fitted by EECs that semi-circle curve in high frequency appears from the parallel combining of bulk resistance $\left(R_{b}\right)$ and bulk capacitance (constant phase element, CPE) of the SPEs 1 [20,31]. In contrast, a half semi-circle is defined as electrode polarization with $\mathrm{Li}^{+}$ions diffusion in the presence of Warburg impedance [27]. In the SPEs 2 (Figure 1.b), impedance curves show a half semi-circle in high frequency following straight-line at low frequency. A lower bulk effect of the SPEs 2 denotes capacitance and CPE in parallel. The CPE connection in series is assigned as electric double layer capacitance (EDLC) creation at low frequency due to the free charges accumulation at the electrode-electrolyte interface [32,33]. Meanwhile, the double depressed semi-circle in SPEs 3 (Figure 1.c) have higher impedance values than SPEs 2 but lower than SPEs 1. But, two depressed semi-circles is caused by the combination of parallel between $R_{b}$ and CPE from ions in series with another $R_{b}$ and CPE that may be appear from grain boundaries of $\mathrm{LiClO}_{4}$

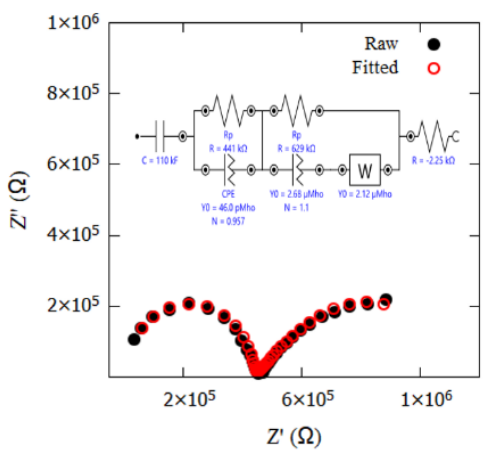

(a)

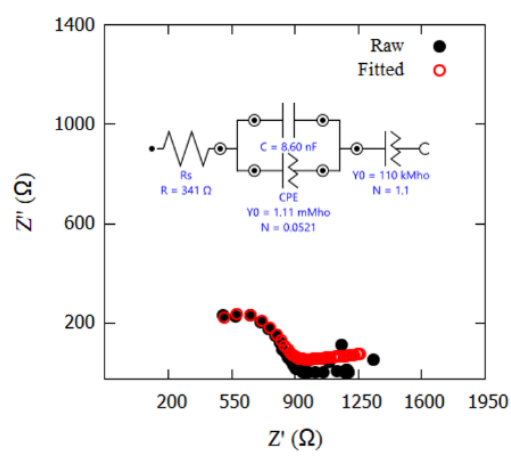

(b)

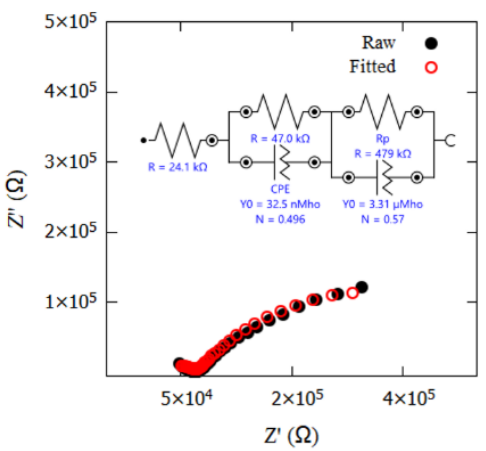

(c)

Figure 1. Nyquist plots of (a) SPEs 1, (b) SPEs 2, and (c) SPEs 3 fitted with Electrical Equivalent Circuits (EECs) models.

\subsection{Dielectric permittivity analysis.}

The dielectric curves was performed in real $\left(\varepsilon^{\prime}\right)$ and imaginary $\varepsilon^{\prime \prime}$ parts as shown in Figure 2. Principally, $\varepsilon^{\prime}$ represents an ability of SPEs to store energy in loading charge carriers for ion diffusion process, whereas $\varepsilon^{\prime \prime}$ called as an ability of SPEs to dissipate energy for ion associaton under electric fields [28,34,35]. Both types of dielectric permittivity can be obtained following the equation (1) and (2) [36,37].

$$
\varepsilon^{\prime}=\frac{Z^{\prime \prime}}{\omega C_{0}\left({Z^{\prime}}^{2}+Z^{\prime \prime 2}\right)}
$$




$$
\varepsilon^{\prime \prime}=\frac{Z^{\prime}}{\omega C_{0}\left(Z^{\prime \prime 2}+Z^{\prime 2}\right)}
$$

where, $\varepsilon^{\prime}, \varepsilon^{\prime \prime}, Z^{\prime}, Z^{\prime \prime}, \omega$ and $C_{0}$ are real dielectric, imaginary dielectric, real impedance, imaginary impedance, angular frequency, and capacitance in vacuum.

The curves which are resulted have a similar pattern depends on frequency. But, the saturation points of dielectric from each sample are different. The peaks at a low frequency of $\varepsilon^{\prime}$ assigned as electrode polarization that leads to charge accumulation or Li-ion immobilization between electrode-electrolyte interface [38]. Then, the saturation at high frequency is claimed as dielectric relaxation [39]. Whereas, $\varepsilon^{\prime \prime}$ peaks at low frequency assigned as dielectric loss which are needed for ion association [40]. Figures 2.a and 2.b show $\varepsilon^{\prime}$ and $\varepsilon^{\prime \prime}$ curves of SPEs 1 which are started with peaks at low frequency and saturated closely in the middle frequency. It assumed that polarization process have medium range to accumulate and associate the $\mathrm{Li}$ ions during transport process between electrode-electrolyte interface. Meanwhile, if we observe the $\varepsilon^{\prime}$ and $\varepsilon^{\prime \prime}$ curves in Figures 2.c and 2.d, SPEs 2 has a better dielectric properties than SPEs 1 due to higher peaks and short saturation in low frequencies. This situation relates with short relaxation process which is caused by high charge density [36]. Thus, SPEs 2 performed good electrical and dielectric properties which are assumed that ionic transport works in short-range area of SPEs 2. However, this situation returned to the lack dielectric properties, where $\varepsilon^{\prime}$ and $\varepsilon^{\prime \prime}$ curves in SPEs 3 in Figures 2.e and 2.f is decrease but closely high than SPEs 1. In addition, the transport process in SPEs 3 looks like poor due to the range between peaks and saturation points presence at middle frequencies. Therefore, we conclude that SPEs 3 have a good electrical and dielectric properties than SPEs 1, but lack in ionic transport process.
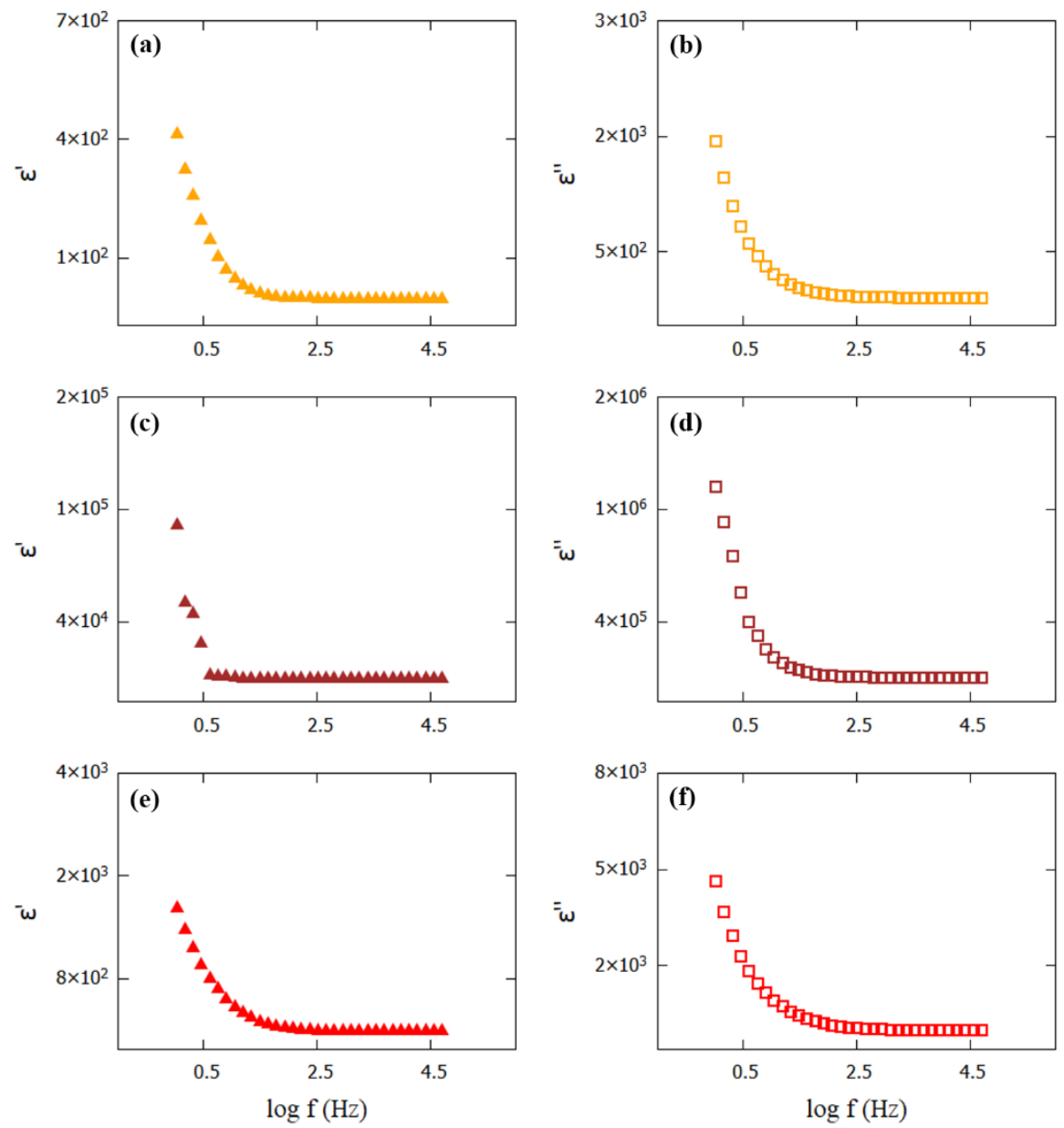
Figure 2. Various real (left side) and imaginary (right side) parts of dielectric permittivity which are resulted from all SPEs.

\subsection{DC ionic conductivity vs dielectric constant.}

The ionic conductivity $\left(\sigma_{D C}\right)$ against dielectric constant $\varepsilon^{\prime}$ values (Table 2 ) of the SPEs commonly depends on ion and polymer chain mobility, and bulk resistance values $\left(R_{b}\right)$ which is obtained from impedance plots. Generally, $\sigma_{D C}$ were calculated in room temperature using equation (3) $[36,41,42]$.

$$
\sigma_{D C}=\frac{l}{R b \times A}
$$

where, $l, R b$, and $A$ are ionic conductivity, thickness, bulk resistance, and surface area of SPEs.

The obtained $\sigma_{D C}$ against $\varepsilon^{\prime}$ values corresponding to $\mathrm{LiClO}_{4}$ concentration as can be seen in Figure 3. SPEs 1 without $\mathrm{LiClO}_{4}$ addition has a lower $\sigma_{D C}$ due to high impedance or $R b$ value. The significant enhancement of $\sigma_{D C}$ in SPEs 2 due to $\mathrm{Li}^{+}$content from $\mathrm{LiClO}_{4}$ which is enhanced its charge density [43]. In addition, $\sigma_{D C}$ returned to decrease significantly in SPEs 3 with $20 \% \mathrm{LiClO}_{4}$. In previous study, the exessive of $\mathrm{LiClO}_{4}$ content triggered an ionic pairing effect following recrystallization of SPEs [44]. Thus, it inhibits ion transport process between electrode-electrolyte interface.

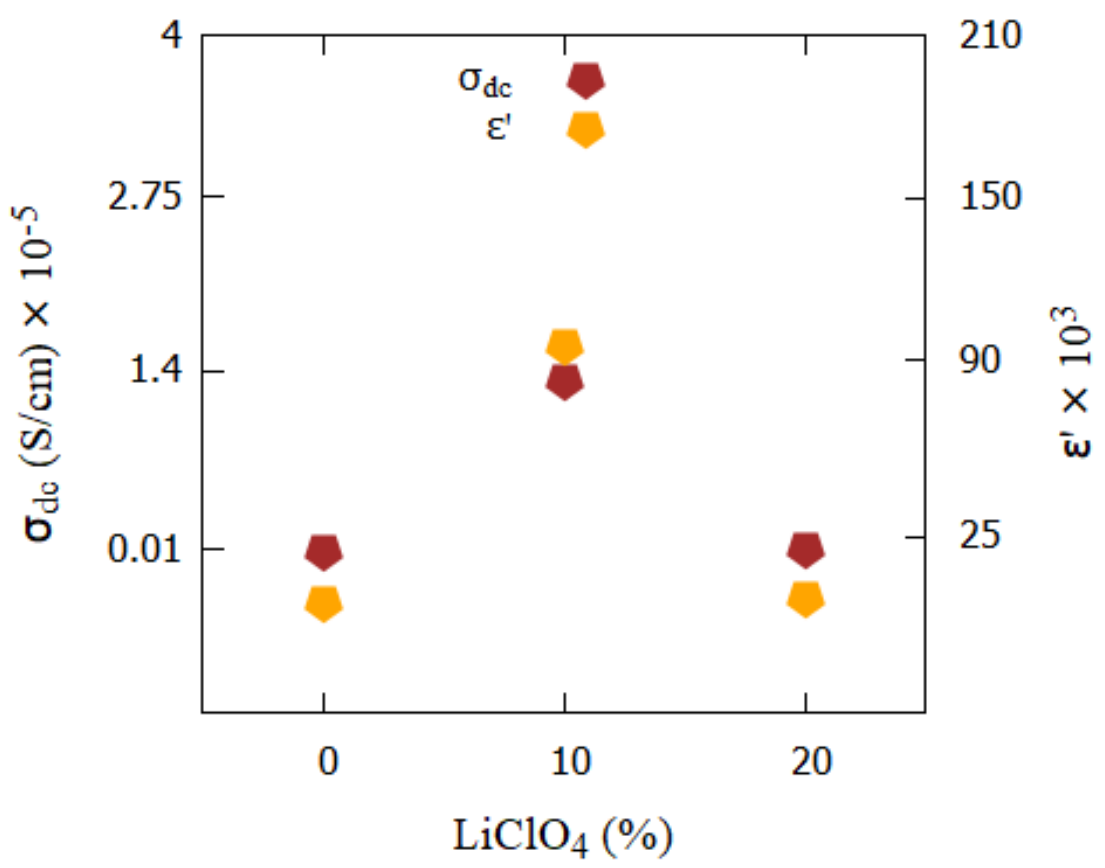

Figure 3. DC ionic conductivity vs dielectric constant values depended on $\mathrm{LiClO}_{4}$ concentration.

Table 2. List of sample names of SPEs with various ionic conductivities, bulk resistances, and dielectric constant.

\begin{tabular}{l|l|l|l} 
Sample names & $\boldsymbol{\sigma}_{\boldsymbol{D C}}(\mathbf{S} / \mathbf{c m})$ & $\boldsymbol{R} \boldsymbol{b}(\boldsymbol{\Omega})$ & $\boldsymbol{\varepsilon}^{\prime}$ \\
\hline SPEs 1 & $2.21 \times 10^{-8}$ & 459710 & 415.96 \\
\hline SPEs 2 & $1.32 \times 10^{-5}$ & 956 & 95638.09 \\
\hline SPEs 3 & $1.54 \times 10^{-7}$ & 65648 & 1904.13 \\
\hline
\end{tabular}

\subsection{Loss tangent analysis.}

This parameter is used to explain the dielectric relaxation process in SPEs. Mathematically, loss tangent is obtained by using equaiton (4) [45]. 


$$
\tan \delta=\frac{\varepsilon^{\prime \prime}}{\varepsilon^{\prime}}
$$

$\tan \delta$ performed in Figure 4 as a function of frequency for all SPEs. The curves increased with increasing frequency until reaching a maximum peak and saturated at a higher frequency. Principally, an increasing $\tan \delta$ curves at the lower frequency indicated that ohmic components as current is higher than capacitive components. Then, the current is decreased at a higher frequency due to the increase of capacitive components [46-48]. SPEs 1 has a lower peak than others, it assumed as low current of charge carriers in polymer chains due to the absence of ions. But, it has a good transport where SPEs 1 can flows the charges in low frequency. Meanwhile, SPEs 2 performed with a better result due to the higher peak, which is resulted in the lower frequency. This case is linear with previous results such as complex impedance and dielectric properties that SPEs 2 has better electrical, dielectric properties, and fastest ion transport with the presence of $\mathrm{Li}$ ions content. However, too much $\mathrm{LiClO}_{4}$ triggered ionic pairs phenomena which inhibited ion transport and decreased its electrical performance [49]. Therfore, $\tan \delta$ peak of SPEs 3 place at a higher frequency.

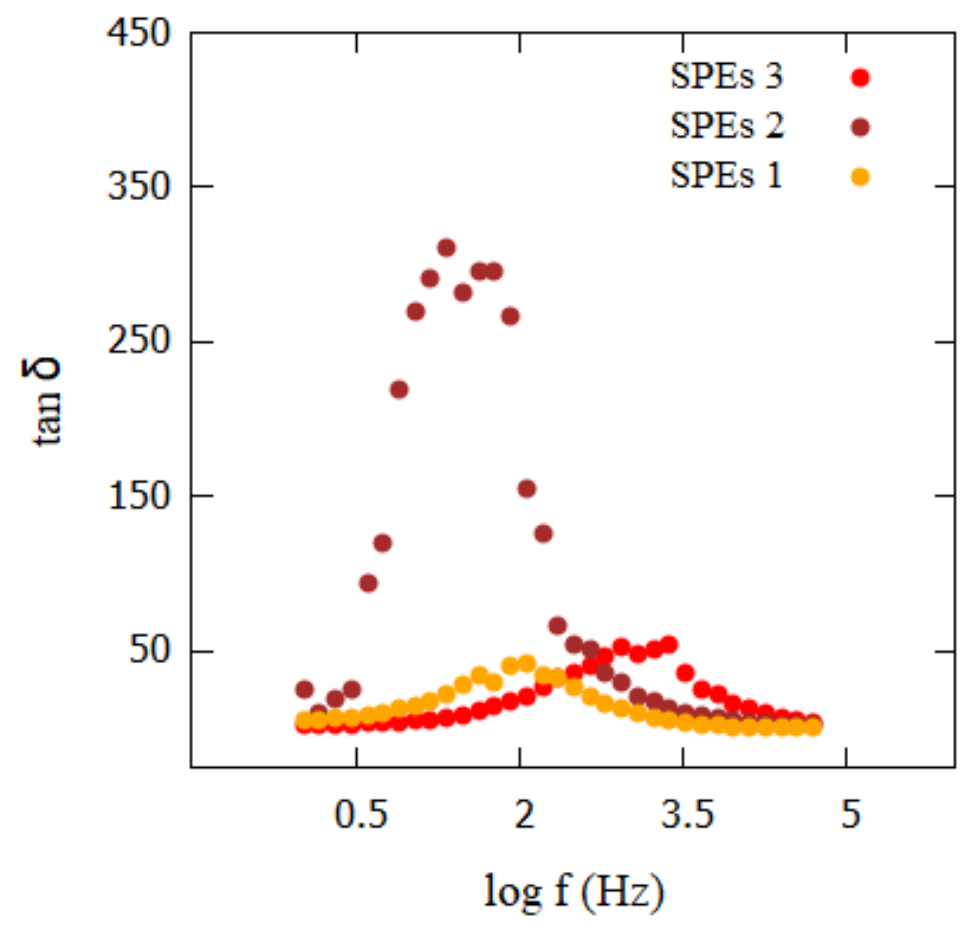

Figure 4. $\tan \delta$ curves of all SPEs with various peaks as a function of frequency.

\subsection{Electrochemical stability.}

LSV curves for All SPEs depicts in Figure 5. A small current was performed through the working electrode until the voltage reached a decomposition at $0.87 \mathrm{~V}$ for SPEs 1 (Figure 5.a) without $\mathrm{LiClO}_{4}$ addition. Meanwhile, the small current is more stable in SPEs 2 (Figure 5.b) and SPEs 3 (Figure 5.c), which reached voltage decomposition at $2.14 \mathrm{~V}$ and $2.25 \mathrm{~V}$, respectively. This results provide information on the electrochemical stability of SPEs-based CMC with or without $\mathrm{LiClO}_{4}$ salt, where SPEs can be applied in electrochemical devices at a potential range where it doesn't experience oxidation or reduction in battery cells [50,51]. Therefore, $\mathrm{LiClO}_{4}$ addition gives more electrochemical stability in SPEs-based CMC compared without $\mathrm{LiClO}_{4}$ addition. 


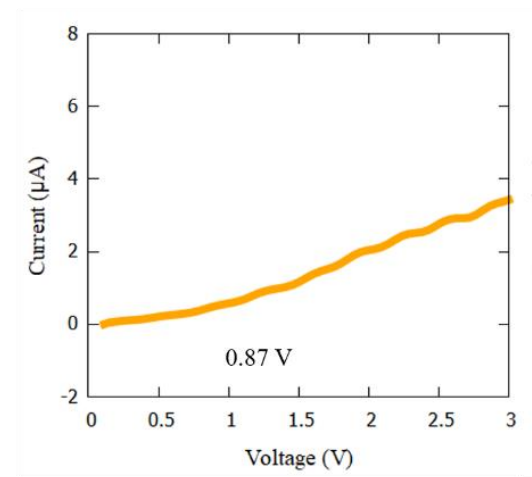

(a)

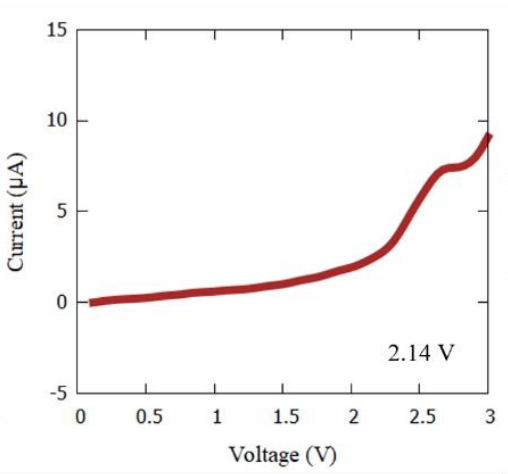

(b)

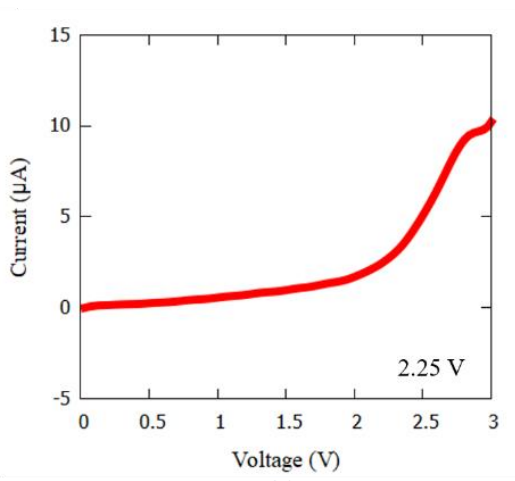

(c)

Figure 5. Electrochemical stability of (a) SPEs 1, (b) SPEs 2, and (c) SPEs 3 from LSV measurement with various voltage decomposition.

\section{Conclusions}

All SPEs are successfully synthesized and packaged to coin cells lithium batteries with various electrical and dielectric properties. SPEs 2 has a better ionic conductivity in $1.32 \times 10^{-}$ ${ }^{5} \mathrm{~S} / \mathrm{cm}$ and dielectric properties such as fastes ionic transport than others which are proven from $\tan \delta$ result. Moreover, electrochemical stability is increase in SPEs with $\mathrm{LiClO}_{4}$ addition, where SPEs 3 has a better electrochemical stability in $2.25 \mathrm{~V}$, but it has poor electrical conductivity and dielectric properties. Therefore, the proportional $\mathrm{LiClO}_{4}$ addition in this SPEs is $10 \%$ based on its electrical and dielectric properties.

\section{Funding}

This research received no external funding.

\section{Acknowledgments}

The authors gratefully acknowledge the experimental supports for this study to Battery Group Research, Research Center for Physics, Indonesian Institute of Sciences.

\section{Dedication}

Dedicated to Doctor Bambang Prihandoko who passed away on June $11^{\text {st }}, 2021$ at the age of $55^{\text {th }}$ years.

\section{Conflicts of Interest}

The authors declare no conflict of interest.

\section{References}

1. Arya, A.; Sharma, A.L. Effect of salt concentration on dielectric properties of Li-ion conducting blend polymer electrolytes. J. Mater. Sci. Mater. Electron. 2018, 29, 17903-17920, doi:10.1007/s10854-0189905-3.

2. Wu, M.; Xu, B.; Ouyang, C. Physics of electron and lithium-ion transport in electrode materials for Li-ion batteries. Chinese Phys. B 2015, 25, 018206, doi:10.1088/1674-1056/25/1/018206.

3. Ren, W.; Huang, Y.; Xu, X.; Liu, B.; Li, S.; Luo, C.; Li, X.; Wang, M.; Cao, H. Gel polymer electrolyte with high performances based on polyacrylonitrile composite natural polymer of lignocellulose in lithium ion battery. J. Mater. Sci. 2020, 55, 12249-12263, doi:10.1007/s10853-020-04888-w.

4. Tenhaeff, W.E.; Yu, X.; Hong, K.; Perry, K.A.; Dudney, N.J. Ionic Transport Across Interfaces of Solid Glass and Polymer Electrolytes for Lithium Ion Batteries. J. Electrochem. Soc. 2011, 158, A1143, 
doi:10.1149/1.3625281.

5. Li, Y.H.; Wu, X.L.; Kim, J.H.; Xin, S.; Su, J.; Yan, Y.; Lee, J.S.; Guo, Y.G. A novel polymer electrolyte with improved high-temperaturetolerance up to $170{ }^{\circ} \mathrm{C}$ for high-temperature lithium-ion batteries. J. Power Sources 2013, 244, 234-239, doi:10.1016/j.jpowsour.2013.01.148.

6. Tarascon, J.M.; Armand, M. Issues and challenges facing rechargeable lithium batteries. Nature 2001, 414, 359-367, doi:10.1038/35104644.

7. Liu, J.; Pickett, P.D.; Park, B.; Upadhyay, S.P.; Orski, S. V.; Schaefer, J.L. Non-solvating, side-chain polymer electrolytes as lithium single-ion conductors: Synthesis and ion transport characterization. Polym. Chem. 2020, 11, 461-471, doi:10.1039/c9py01035a.

8. Aziz, S.B.; Abdullah, O.G.; Saeed, S.R.; Ahmed, H.M. Electrical and dielectric properties of copper ion conducting solid polymer electrolytes based on chitosan: $\mathrm{CBH}$ model for ion transport mechanism. Int. J. Electrochem. Sci. 2018, 13, 3812-3826, doi:10.20964/2018.04.10.

9. Du, H.; Wu, Z.; Xu, Y.; Liu, S.; Yang, H. Poly(3,4-ethylenedioxythiophene) based solid-state polymer supercapacitor with ionic liquid gel polymer electrolyte. Polymers (Basel). 2020, 12, doi:10.3390/polym12020297.

10. Xu, H.; Xie, J.; Liu, Z.; Wang, J.; Deng, Y. Carbonyl-coordinating polymers for high-voltage solid-state lithium batteries: Solid polymer electrolytes. MRS Energy Sustain. 2020, 7, 1-25, doi:10.1557/mre.2020.3.

11. Jaschin, P.W.; Gao, Y.; Li, Y.; Bo, S.H. A materials perspective on magnesium-ion-based solid-state electrolytes. J. Mater. Chem. A 2020, 8, 2875-2897, doi:10.1039/c9ta11729f.

12. Zhu, Y.S.; Xiao, S.Y.; Li, M.X.; Chang, Z.; Wang, F.X.; Gao, J.; Wu, Y.P. Natural macromolecule based carboxymethyl cellulose as a gel polymer electrolyte with adjustable porosity for lithium ion batteries. $J$. Power Sources 2015, 288, 368-375, doi:10.1016/j.jpowsour.2015.04.117.

13. Rayung, M.; Aung, M.M.; Azhar, S.C.; Abdullah, L.C.; Su'ait, M.S.; Ahmad, A.; Jamil, S.N.A.M. Bio-based polymer electrolytes for electrochemical devices: Insight into the ionic conductivity performance. Materials (Basel). 2020, 13, doi:10.3390/ma13040838.

14. Saadiah, M.A.; Zhang, D.; Nagao, Y.; Muzakir, S.K.; Samsudin, A.S. Reducing crystallinity on thin film based CMC/PVA hybrid polymer for application as a host in polymer electrolytes. J. Non. Cryst. Solids 2019, 511, 201-211, doi:10.1016/j.jnoncrysol.2018.11.032.

15. Ali, B.; Mohammed, A.B.R. Ionic conductivity of chitosan-lithium electrolyte in biodegradable battery cell. Indones. J. Chem. 2020, 20, 655-660, doi:10.22146/ijc.45283.

16. Peters, F.; Langer, F.; Hillen, N.; Koschek, K.; Bardenhagen, I.; Schwenzel, J.; Busse, M. Correlation of mechanical and electrical behavior of polyethylene oxide-based solid electrolytes for all-solid state lithiumion batteries. Batteries 2019, 5, doi:10.3390/batteries5010026.

17. Aziz, S.B.; Mamand, S.M. The Study of dielectric properties and conductivity relaxation of ion conducting chitosan: NaTf based solid electrolyte. Int. J. Electrochem. Sci. 2018, 13, 10274-10288, doi:10.20964/2018.11.05.

18. Ma, X.; Yu, J.; He, K.; Wang, N. The effects of different plasticizers on the properties of thermoplastic starch as solid polymer electrolytes. Macromol. Mater. Eng. 2007, 292, 503-510, doi:10.1002/mame.200600445.

19. Abidin, S.Z.Z.; Hassan, O.H.; Ali, A.M.M.; Yahya, M.Z.A. Electrochemical studies on cellulose acetateLiBOB polymer gel electrolytes. 8th Asian-Australasian Conf. Compos. Mater. 2012, ACCM 2012 Compos. Enabling Tomorrow's Ind. Today 2012, 1, 696-701.

20. Aziz, S.B.; Hamsan, M.H.; Abdullah, R.M.; Kadir, M.F.Z. A promising polymer blend electrolytes based on chitosan: Methyl cellulose for EDLC application with high specific capacitance and energy density. Molecules 2019, 24, 2503, doi:10.3390/molecules24132503.

21. Ndruru, S.T.C.L.; Wahyuningrum, D.; Bundjali, B.; Arcana, I.M. Preparation and characterization of biopolymer electrolyte membranes based on liclo4-complexed methyl cellulose as lithium-ion battery separator. J. Eng. Technol. Sci. 2020, 52, 28-50, doi:10.5614/j.eng.technol.sci.2020.52.1.3.

22. Saadiah, M.H.; Zhang, D.; Nagao, Y.; Samsudin, A.S. Molecularly Conductive Behavior of Blended Polymer Electrolyte-based CMC/PVA. Makara J. Technol. 2019, 23, 27, doi:10.7454/mst.v23i1.3639.

23. Abdullah, O.G.; Aziz, S.B.; Rasheed, M.A. Incorporation of NH4NO3 into MC-PVA blend-based polymer to prepare proton-conducting polymer electrolyte films. Ionics (Kiel). 2018, 24, 777-785, doi:10.1007/s11581-017-2228-1.

24. Hegde, S.; Ravindrachary, V.; Praveena, S.D.; Ismayil; Guruswamy, B.; Sagar, R.N. Microstructural, dielectric, and transport properties of proton-conducting solid polymer electrolyte for battery applications. Ionics (Kiel). 2020, 26, 2379-2394, doi:10.1007/s11581-019-03383-w.

25. Shukla, N.; Thakur, A.K.; Shukla, A.; Marx, D.T. Ion conduction mechanism in solid polymer electrolyte: An applicability of almond-west formalism. Int. J. Electrochem. Sci. 2014, 9, 7644-7659.

26. Laxmayyaguddi, Y.; Mydur, N.; Shankar Pawar, A.; Hebri, V.; Vandana, M.; Sanjeev, G.; Hundekal, D. Modified Thermal, Dielectric, and Electrical Conductivity of PVDF-HFP/LiClO 4 Polymer Electrolyte Films by $8 \mathrm{MeV}$ Electron Beam Irradiation. ACS Omega 2018, 3, 14188-14200, doi:10.1021/acsomega.8b01097.

27. Kanimozhi, G.; Vinoth, S.; Harish, K.; Srinadhu, E.S.; Satyanarayana, N. Conductivity and dielectric permittivity studies of KI-based nanocomposite (PEO/PMMA/KI/I2/ZnO nanorods) polymer solid 
electrolytes. Polym. Compos. 2019, 40, 2919-2928, doi:10.1002/pc.25123.

28. Aziz, S.B.; Marif, R.B.; Brza, M.A.; Hamsan, M.H.; Kadir, M.F.Z. Employing of Trukhan model to estimate ion transport parameters in PVA based solid polymer electrolyte. Polymers (Basel). 2019, 11, 1694, doi:10.3390/polym11101694.

29. Aziz, S.B.; Brza, M.A.; Mohamed, P.A.; Kadir, M.F.Z.; Hamsan, M.H.; Abdulwahid, R.T.; Woo, H.J. Increase of metallic silver nanoparticles in Chitosan:AgNt based polymer electrolytes incorporated with alumina filler. Results Phys. 2019, 13, 1-10, doi:10.1016/j.rinp.2019.102326.

30. Aziz, S.B.; Brza, M.A.; Saed, S.R.; Hamsan, M.H.; Kadir, M.F.Z. Ion association as a main shortcoming in polymer blend electrolytes based on CS:PS incorporated with various amounts of ammonium tetrafluoroborate. J. Mater. Res. Technol. 2020, 9, 5410-5421, doi:10.1016/j.jmrt.2020.03.067.

31. Verma, M.L.; Sahu, H.D. Study on ionic conductivity and dielectric properties of PEO-based solid nanocomposite polymer electrolytes. Ionics (Kiel). 2017, 23, 2339-2350, doi:10.1007/s11581-017-2063-4.

32. Dannoun, E.M.A.; Aziz, S.B.; Brza, M.A.; Nofal, M.M.; Asnawi, A.S.F.M.; Yusof, Y.M.; Al-Zangana, S.; Hamsan, M.H.; Kadir, M.F.Z.; Woo, H.J. The study of plasticized solid polymer blend electrolytes based on natural polymers and their application for energy storage EDLC devices. Polymers (Basel). 2020, 12, 1-19, doi:10.3390/polym12112531.

33. Aziz, S.B.; Abidin, Z.H.Z.; Arof, A.K. Influence of silver ion reduction on electrical modulus parameters of solid polymer electrolyte based on chitosansilver triflate electrolyte membrane. Express Polym. Lett. 2010, 4, 300-310, doi:10.3144/expresspolymlett.2010.38.

34. Putro, P.A.; Yudasari, N.; Irdawati, Y.; Sulaeman, A.S.; Maddu, A. Reducing the Electrical Conductivity of $\mathrm{ZnO} / \mathrm{Ag}$ Nanofiller for Solid Polymer Electrolytes Prepared by Laser Ablation in Polylactic Acid Solution. J. Fis. dan Apl. 2021, 17, 41-47, doi:10.12962/j24604682.v17i2.8135.

35. Badry, R.; El-Khodary, S.; Elhaes, H.; Nada, N.; Ibrahim, M. Optical, conductivity and dielectric properties of plasticized solid polymer electrolytes based on blends of sodium carboxymethyl cellulose and polyethylene oxide. Opt. Quantum Electron. 2021, 53, 1-15, doi:10.1007/s11082-020-02649-2.

36. Tripathi, N.; Shukla, A.; Thakur, A.K.; Marx, D.T. Dielectric Modulus and Conductivity Scaling Approach to the Analysis of Ion Transport in Solid Polymer Electrolytes. Polym. Eng. Sci. 2020, 60, 297-305, doi:10.1002/pen.25283.

37. Aziz, S.B.; Hisham, S.; Shah, S.; Abidin, Z.H.Z. Characteristics of Dye-Sensitized Solar Cell. 2020, doi:10.3390/molecules25184115.

38. Sahu, G.; Das, M.; Yadav, M.; Sahoo, B.P.; Tripathy, J. Dielectric relaxation behavior of silver nanoparticles and graphene oxide embedded poly(vinyl alcohol) nanocomposite film: An effect of ionic liquid and temperature. Polymers (Basel). 2020, 12, 1-16, doi:10.3390/polym12020374.

39. Yaragalla, S.; Sarath Chandran, C.; Kalarikkal, N.; Subban, R.H.Y.; Chan, C.H.; Thomas, S. Effect of reinforcement on the barrier and dielectric properties of epoxidized natural rubber-graphene nanocomposites. Polym. Eng. Sci. 2015, 55, 2439-2447, doi:10.1002/pen.24131.

40. Arya, A.; Sadiq, M.; Sharma, A.L. Salt concentration and temperature dependent dielectric properties of blend solid polymer electrolyte complexed with NaPF6. Mater. Today Proc. 2019, 12, 554-564, doi:10.1016/j.matpr.2019.03.098.

41. Muhamad, A.; Wolf, S.; Roschger, M.; Hacker, V. Poly ( vinyl alcohol ) -Based Anion Exchange Membranes for Alkaline Direct Ethanol Fuel Cells. 2021, 10, 435-443, doi:10.14710/ijred.2021.33168.

42. Verdier, N.; Lepage, D.; Zidani, R.; Prébé, A.; Aymé-Perrot, D.; Pellerin, C.; Dollé, M.; Rochefort, D. CrossLinked Polyacrylonitrile-Based Elastomer Used as Gel Polymer Electrolyte in Li-Ion Battery. ACS Appl. Energy Mater. 2020, 3, 1099-1110, doi:10.1021/acsaem.9b02129.

43. Gohel, K.; Kanchan, D.K. Ionic conductivity and relaxation studies in PVDF-HFP: PMMA-based gel polymer blend electrolyte with LiClO4 salt. J. Adv. Dielectr. 2018, 8, 1-13, doi:10.1142/S2010135X18500054.

44. Patra, S.; Thakur, P.; Soman, B.; Puthirath, A.B.; Ajayan, P.M.; Mogurampelly, S.; Karthik Chethan, V.; Narayanan, T.N. Mechanistic insight into the improved Li ion conductivity of solid polymer electrolytes. RSC Adv. 2019, 9, 38646-38657, doi:10.1039/c9ra08003a.

45. Perumal, P.; Christopher Selvin, P.; Selvasekarapandian, S.; Abhilash, K.P. Bio-host pectin complexed with dilithium borate based solid electrolytes for polymer batteries. Mater. Res. Express 2019, 6, 115513, doi:10.1088/2053-1591/ab4724.

46. Aziz, S.B.; Karim, W.O.; Ghareeb, H.O. The deficiency of chitosan: AgNO3 polymer electrolyte incorporated with titanium dioxide filler for device fabrication and membrane separation technology. $J$. Mater. Res. Technol. 2020, 9, 4692-4705, doi:10.1016/j.jmrt.2020.02.097.

47. Putro, P.A.; Sulaeman, A.S.; Maddu, A. The Role of C-dots/(MnO2)x(x = 0, 2, 4, mM) on Enhancing the Ion Transport in Poly (Ethylene Oxide) Based Solid Polymer Electrolytes: The Optical and Electrical Characteristics. J. Phys. Conf. Ser. 2021, 1805, 012020, doi:10.1088/1742-6596/1805/1/012020.

48. Abdulkadir, B.A.; Dennis, J.O.; Shukur, M.F.B.A.; Nasef, M.M.E.; Usman, F. Study on Dielectric Properties of Gel Polymer Electrolyte Based on PVA-K2CO3 Composites. Int. J. Electrochem. Sci. 2021, 16, 1-15, doi:10.20964/2021.01.34.

49. Mustapa, S.R.; Aung, M.M.; Rayung, M. Physico-chemical, thermal, and electrochemical analysis of solid 
polymer electrolyte from vegetable oil-based polyurethane. Polymers (Basel). 2021, 13, 1-20, doi:10.3390/polym13010132.

50. Noor, N.A.M.; Isa, M.I.N. Investigation on transport and thermal studies of solid polymer electrolyte based on carboxymethyl cellulose doped ammonium thiocyanate for potential application in electrochemical devices. Int. J. Hydrogen Energy 2019, 44, 8298-8306, doi:10.1016/j.ijhydene.2019.02.062.

51. Aziz, S.B.; Hamsan, M.H.; Karim, W.O.; Kadir, M.F.Z.; Brza, M.A.; Abdullah, O.G. High proton conducting polymer blend electrolytes based on chitosan: Dextran with constant specific capacitance and energy density. Biomolecules 2019, 9, 1-22, doi:10.3390/biom9070267. 